05,12

\title{
Структура и магнитные свойства слоевых нанопроволок из $3 d$-металлов, полученных методом матричного синтеза
}

\author{
( Д.А. Черкасов ${ }^{1}$, Д.Л. Загорский ${ }^{1, \uparrow, ~ Р . И . ~ Х а и ̆ б у л л и н ~}{ }^{2}$, А.Э. Муслимов ${ }^{1}$, И.М. Долуденко ${ }^{1}$ \\ ${ }^{1}$ Институт кристаллографии им. А.В. Шубникова ФНИЦ „Кристаллография и фотоника“ РАН, \\ Москва, Россия \\ ${ }^{2}$ Казанский физико-технический институт им. Е.К. Завойского ФИЦ Казанский научный центр РАН, \\ Казань, Россия \\ ฯ E-mail: dzagorskiy@gmail.com
}

Поступила в Редакцию 26 марта 2020 г.

В окончательной редакции 26 марта 2020 г.

Принята к публикации 2 апреля 2020 г.

Методом матричного синтеза на основе полиэтилентерефталатных трековых мембран получены массивы слоевых нанопроволок с диаметром $100 \mathrm{~nm}$, состоящие из чередующихся слоев $\mathrm{Ni} / \mathrm{Cu}$ и $\mathrm{Co} / \mathrm{Cu}$. Исследованы процессы гальванического осаждения и определены режимы получения слоевых нанопроволок с различной толщиной для магнитных ( $\mathrm{Ni}$ или $\mathrm{Co}$ ) и немагнитной $(\mathrm{Cu})$ компонент слоя. Проведено электронномикроскопическое исследование для верификации режимов получения слоевых нанопроволок и уточнения геометрических размеров чередующихся слоев. Методами вибрационной магнитометрии измерены кривые намагничивания полученных массивов слоевых нанопроволок при комнатной температуре для двух предельных ориентаций сканирующего магнитного поля: параллельно и перпендикулярно по отношению к оси роста нанопроволок. Показано, что магнитная анизотропия свойств массива нанопроволок определяется не только химическим составом, но и толщиной и периодом чередования слоев магнитных металлов в нанопроволоках. Проведены численные оценки зависимости магнитостатической энергии и величины размагничивающего поля в синтезированных слоевых нанопроволоках от фактора их заполнения магнитным металлом, которые качественно согласуются с экспериментальными наблюдениями.

Ключевые слова: нанопроволоки, электроосаждение, магнетизм, матричный синтез.

DOI: $10.21883 /$ FTT.2020.09.49782.28H

\section{1. Введение}

Квазиодномерные наноструктуры - нанопроволоки (НП), нанонити или наностержни являются яркими и интереснейшими физическими объектами наномира. Одним из способов получения таких наноструктур является матричный (темплатный) синтез. В настоящей работе рассматривается один из наиболее популярных вариантов: в качестве матрицы (темплата) берется полимерная пористая (трековая) мембрана, в поры которой затем вводятся металлы путем электрохимического осаждения. Все эти процессы хорошо изучены, их режимы и параметры варьируются в широких пределах, а сами процессы контролируются и воспроизводятся с высокой точностью. Вследствие этого матричный синтез дает возможность получения массива нанопроволок самых разных типов. Получение массивов НП было отработано еще в 90-е годы прошлого века [1]. Со временем разнообразие получаемых НП непрерывно возрастало от гомогенных НП, состоящих из одного типа металла или сплава различных металлов, к гетерогенным НП, содержащих чередующиеся слои различных металлов (т.н. слоевым НП). В настоящее время синтезируются также и „градиентные“ НП, в которых элементный и/или фазовый состав плавно изменяется по длине нанопроволоки, а также „полые“ НП (нанотрубки) и нанопроволоки типа „стержень-оболочка“.

Из вышеперечисленных типов НП особый интерес для индустрии магнитной записи и хранения информации, а также для спинтроники представляют слоевые НП, содержащие магнитные металлы или сплавы в качестве чередующихся слоев [2].

Идее об использовании массивов НП для магнитной записи с высокой плотностью уже более 30 лет. В работах давались различные оценки достижимой плотности записи - в 90-х годах прошлого столетия (работа [2]) это было $10^{6} \mathrm{Mb} / \mathrm{in}^{2}$. В начале этого века давалась уже другая оценка - до $10^{12} \mathrm{~b} / \mathrm{in}^{2}$ [3]. В 2010 году авторы [4] скептически оценили возможности магнитной записи с высокой плотностью с применением массивов НП. Однако затем был предложен другой подход использовать дополнительно еще и длину самой НП, т.е. „третье измерение“ для магнитной записи. Так в работе [5] было предложено использовать доменную структуру, формируемую в отдельно взятой НП, в качестве третьего измерения. Другими словами, каждая НП может содержать не один, а несколько бит информации за счет наличия в НП магнитных доменов. При этом, в соответствии с концепцией „Racetrack memory“, доменные стенки в НП могут не только перемещаться за счет импульсов спин-поляризованного тока, но сами 
домены могут менять свою ориентацию, что дает (пока в теории) возможность записи и перезаписи информации с гораздо большей плотностью. Отмечается, что использование слоевых НП, состоящих из чередующихся слоев различных магнитных металлов, увеличит эффективность ,пиннинга“ доменных стенок, что представляется важным для создания „трехмерной“ памяти на массиве слоевых НП. Кроме этого, в работе [6] описаны перспективы использования слоевых НП из ферромагнитных металлов в области генерации (или детектирования) электромагнитного излучения терагерцовой частоты.

Другим типом слоевых НП являются структуры, состоящие из чередующихся магнитных и немагнитных слоев (промежутков, спейсеров). В этом направлении представляет интерес создание как многослойных тонкопленочных магнитных структур, так и слоевых НП, в которых может быть реализовано так называемое неколлинеарное распределение вектора намагниченности. Такие наноструктурированные объекты могут также использоваться в устройствах хранения и обработки информации, поскольку их транспортные свойства зависят от пространственного распределения вектора намагниченности [7]. В частности, тонкопленочные многослойные системы были реализованы в работе [8], где три различных кобальтовых слоя создавались методом магнетронного напыления на кремниевой подложке с оксидом алюминия в качестве спейсера. В работе построена теоретическая модель, изучена зависимость магнитосопротивления и доказано, что такая структура (в нулевом внешнем магнитном поле) находится в неколлинеарном спиральном состоянии. Такие структуры можно перемагничивать спин-поляризованным током, в них могут наблюдаться спин-зависимые транспортные явления. В работе [9] методом электронно-лучевой литографии были получены подобные структуры из кобальта с кремниевыми спейсерами. Исследования таких наноструктур методами магнитной силовой микроскопии (МСM) показали геликоидальное распределение намагниченности, схожее с теоретическим расчетом МСМ-изображения.

Известен ряд работ [10-21], посвященных синтезу и изучению слоевых НП с чередующимися слоями 3d-металлов: магнитных металлов (кобальта, никеля и железа) и немагнитной меди. В частности, в работе [10] описано приготовление НП из чередующихся слоев кобальта и меди, в которых обнаружен эффект гигантского магнетосопротивления (ГМС) величиной около $15 \%$. В [11] описано получение НП $\mathrm{Co} / \mathrm{Cu}$ методом электроосаждения в поры поликарбонатных мембран с порами диаметром $80 \mathrm{~nm}$ и также изучен эффект ГМС. Сравнивались однованновый и двухванновый методы. Сделан вывод о том, что двухванновый метод позволяет избежать со--осаждения меди в кобальтовый слой. В статье [12] также были исследованы НП $\mathrm{Co} / \mathrm{Cu}$, но с большим диаметром $200 \mathrm{~nm}$ и различной толщиной кобальтовых слоев. Показано, что магнитные свойства массива изменялись при изменении аспектного отношения толщины кобальтового слоя к диаметру НП. Авторы сделали предположение, что для НП с тонкими кобальтовыми слоями структура является однодоменной, а с толстыми кобальтовыми слоями - структура переходит в вихревое состояние.

НП с чередующимися слоями никеля и меди также посвящен ряд работ. В статье [13] многослойные НП $\mathrm{Ni} / \mathrm{Cu}$ длиной $6 \mu \mathrm{m}$ были получены в порах поликарбонатных матриц с диаметром от 30 до $100 \mathrm{~nm}$, было

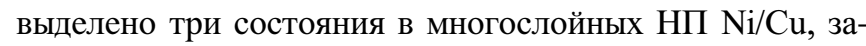
висящих от аспектного отношения. Магнитные свойства слоевой НП сильно зависят от толщины немагнитной прослойки из-за магнитного дипольного взаимодействия. Авторы [14] доказали влияние потенциала роста на состав и микроструктуру слоевых НП $\mathrm{Ni} / \mathrm{Cu}$. Получены и изучены НП (с диаметром 40-140 nm), со слоями с аспектным отношением от 0.1 (форма диска) до 2.5 (форма стержня). Показано, что коэрцитивная сила и остаточная намагниченность сильно зависят как от диаметра и аспектного отношения, так и от дипольного взаимодействия между ферромагнитными слоями. В работе [15] изучены различные типы НП, в том

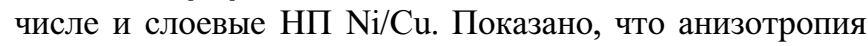
в большой степени определяется дипольным взаимодействием. В статье [16] для получения многослойных $\mathrm{HП} \mathrm{Ni} / \mathrm{Cu}$ в порах пористого оксида алюминия (ПОА) использовался двухванновый метод. Показано, что магнитные характеристики зависят от геометрии слоев; максимальное значение коэрцитивной силы было $822 \mathrm{Oe}$ при прямоугольности 10.949. В работе [17] слоевые НП $\mathrm{Ni} / \mathrm{Cu}$ были получены в порах ПОА: диаметры полученных нанопроволок составляли 42 и $65 \mathrm{~nm}$, а толщина слоев для никеля варьировалась от 10 до $280 \mathrm{~nm}$. Коэрцитивная сила и отношение остаточной намагниченности к намагниченности насыщения (прямоугольность) для продольного направления значительно возрастали при увеличении толщины никелевых слоев. Напротив, для направления, перпендикулярного осям НП, магнитные свойства не зависели от длины слоев. В статье [18] слоевые НП Ni/Cu были получены электроосаждением в поры ПОА: показано, что при увеличении магнитной анизотропии структура становилась более магнитожесткой.

В работах последних лет проводились исследования влияния толщины магнитных слоев и толщины спейсеров на магнитные свойства массивов НП. Так, в работе [19] слоевые НП $\mathrm{Ni} / \mathrm{Cu}$ были выращены в порах ПОА. Рентгеновские измерения показали сильную зависимость текстуры от аспектного отношения в НП. Показано, что для магнитных слоев с малым аспектным отношением доминирует антиферромагнитное упорядочение между слоями никеля. При увеличении толщины никелевых слоев магнитное взаимодействие между ними становится сильнее, приводя к ферромагнитному упорядочению. Роль спейсеров описана в работе [20]: в ней НП $\mathrm{Fe} / \mathrm{Cu}$ диаметром $45 \mathrm{~nm}$ были выращены в порах ПОА. Слои из $\mathrm{Fe}$ постоянной толщины $(50 \mathrm{~nm})$ чередовались с медными слоями (толщиной от 15 до $120 \mathrm{~nm}$ ). Влияние 
толщины немагнитных спейсеров оценивалось методами магнитометрии (FORC) и моделирования.

B нашей ранней работе [21] были описаны результаты предварительных исследований структурных и магнитных свойств двух типов слоевых НП - $\mathrm{Co} / \mathrm{Cu}$ и $\mathrm{Ni} / \mathrm{Cu}$, полученных с использованием пористых матриц из полиэтилентерефталата (ПЭТФ). Методом просвечивающей электронной микроскопии (ПЭМ) была определена толщина и элементный состав полученных слоевых НП. Определена кристаллическая структура образующихся слоев (обычно - ГЦК, в том числе и для кобальта), размер кристаллитов $(20-60 \mathrm{~nm})$ и элементный состав слоев: в НП с медью - практически чистая медь и слои магнитного металла, содержащие до 20\% меди. Получены НП с минимальной толщиной слоев $20 \mathrm{~nm}$. Отметим, что подобные структуры могут быть использованы и для получения так называемых цилиндрических наноразмерных частиц калиброванного размера для применения, например, в биологии [22].

Анализируя совокупность опубликованных работ, можно сделать вывод о том, что слоевые НП, состоящие из чередующихся слоев магнитных и немагнитных металлов, могут иметь несколько потенциальных применений. Практическое применение таких структур сдерживается недостатком знаний о магнитных свойствах и о влиянии условий получения на их структуру и свойства.

Целью настоящей работы являлось дальнейшее развитие исследований, описанных в нашей работе [21], с точки зрения получения на основе пористого ПЭТФ новых массивов слоевых НП $(\mathrm{Co} / \mathrm{Cu}$ и $\mathrm{Ni} / \mathrm{Cu})$ с более широким спектром геометрических параметров и взаиморасположения магнитных и немагнитных слоев и выявления связи размерных параметров слоевых НП с их магнитными свойствами.

\section{2. Образцы и методы}

Матрица и электроосаждение. Для получения слоевых НП в качестве матрицы были использованы полимерные трековые мембраны (производства ОИЯИ, Дубна, диаметр пор $100 \mathrm{~nm}$, плотность пор

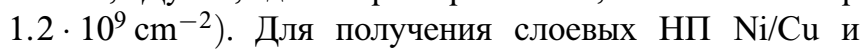
$\mathrm{Co} / \mathrm{Cu}$ в поры мембран проводилось электроосаждение соответствующих слоев металлов. При этом чередование составов задавалось изменением потенциала осаждения.

Использовались электролиты следующих составов: для осаждения $\mathrm{HП} \mathrm{Ni} / \mathrm{Cu}: \mathrm{H}_{3} \mathrm{BO}_{3}-0.5 \mathrm{~mol} / \mathrm{l}$, $\mathrm{NiSO}_{4} \cdot 7 \mathrm{H}_{2} \mathrm{O}-0.7 \mathrm{~mol} / \mathrm{l}, \mathrm{CuSO}_{4} \cdot 5 \mathrm{H}_{2} \mathrm{O}-25 \mathrm{mmol} / \mathrm{l}$. Для осаждения НП $\mathrm{Co} / \mathrm{Cu}: \mathrm{H}_{3} \mathrm{BO}_{3}-0.5 \mathrm{~mol} / \mathrm{l}$, $\mathrm{CoSO}_{4} \cdot 7 \mathrm{H}_{2} \mathrm{O}-0.7 \mathrm{~mol} / 1, \mathrm{CuSO}_{4} \cdot 5 \mathrm{H}_{2} \mathrm{O}-30 \mathrm{mmol} / 1$.

Электроосаждение проводилось в гальванической ячейке (производство СКБ ИК РАН), по двухэлектродной схеме. Отметим, что концентрация меди в растворе была значительно меньше концентрации магнитного металла - это обусловлено особенностями использования бинарного электролита. Осаждение чередующихся слоев различного состава и различной толщины (длины) проводилось в однованновом режиме. Были получены чередующиеся слои толщиной от 20 до $500 \mathrm{~nm}$. В ходе электроосаждения (проводившегося в импульсном режиме, с заданием двух периодически изменяющихся потенциалов) записывались кривые зависимости силы тока от времени, которые позволяли контролировать процесс.

Микр оскопия. Использовался CЭМ JEOL 6000 с приставкой для элементного анализа. Микроскоп работал в режиме вторичных электронов, при ускоряющем напряжении $15 \mathrm{kV}$.

Магнитометрия. Магнитные свойства были исследованы методом вибрационной магнитометрии на коэрцитивном спектрометре [23], позволявшем одновременно, в одном цикле измерений, записывать полевые зависимости как наведенной, так и остаточной намагниченности исследуемого образца. Регистрация кривых магнитного гистерезиса проводилась при комнатной температуре при двух предельных ориентациях сканирующего магнитного поля: параллельно или перпендикулярно к оси роста НП.

\section{3. Результаты и обсуждение}

\section{1. Основные режимы и параметры получения слоевых НП}

Были подобраны оптимальные ростовые напряжения для осаждения каждого из трех металлов (из соответствующих двухкомпонентных растворов): при осаждении НП из $\mathrm{Ni} / \mathrm{Cu}$ для роста медных слоев $-0.7 \mathrm{~V}$, для роста никелевых слоев - $1.8 \mathrm{~V}$; при осаждении НП из $\mathrm{Co} / \mathrm{Cu}$ для роста медных слоев $-0.5 \mathrm{~V}$, для роста кобальтовых слоев - $1.5 \mathrm{~V}$.

В ходе электроосаждения регистрировались кривые зависимости напряжения от времени (величины напряжений в импульсе, а также время длительности импульсов и пауз задавались программой потенциостата) и тока от времени. Полученные графики представлены на рис. 1.

На представленных графиках видно, что изменение тока в целом соответствует изменению прикладываемого напряжения. Вместе с тем, наблюдаются „провалы“ и „сглаживания“ в момент переключения напряжения очевидно, они связаны с переходными процессами и диффузионными ограничениями в узких поровых каналах.

Полученные НП затем исследовались методами микроскопии и магнитометрии (см. ниже), что дало возможность оценки различных режимов и их корректировки. Сравнивались различные режимы гальванического осаждения, и было показано, что для получения чередующихся слоев, толщина которых не изменяется по длине НП, наилучший результат давал метод контроля протекшего заряда: изменение напряжения осаждения 

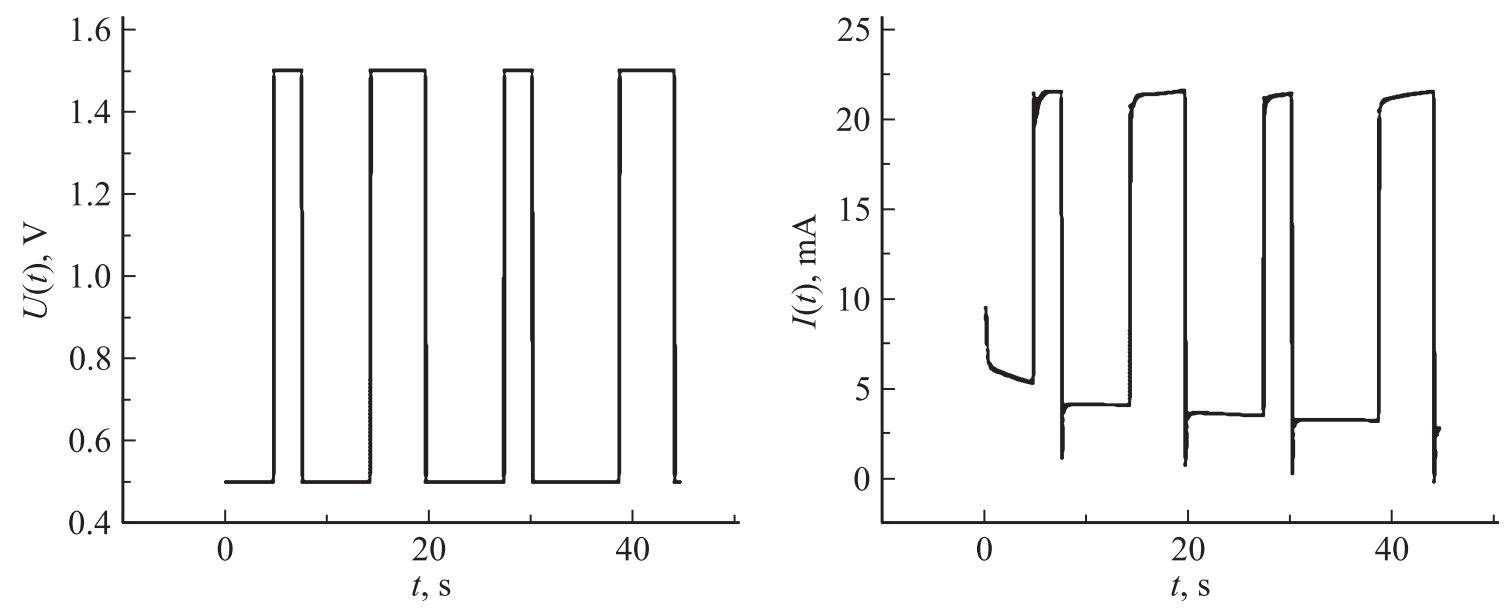

Рис. 1. Графики электроосаждения: слева — временная зависимость напряжения, прикладываемого между электродами, справа зависимость тока от времени.

(для роста последующего слоя) производилось после протекания заданного заряда. Можно отметить, что при этом время осаждения последующих слоев постепенно увеличивалось, так как из-за увеличния сопротивления (одна из причин - истощение электролита в поровом канале) уменьшался ток. (Так, величина тока при осаждении слоев меди в середине НП была примерно в два раза меньше, чем при осаждения первого слоя меди).

Путем подбора длительности ростовых импульсов при росте НП были получены три серии образцов, схематические изображения которых показаны на рис. 2. В первой серии образцов НП состояли из одинаковых по толщине медных и магнитных (никелевых или кобальтовых) слоев, величина которых варьировалась от 50 до $500 \mathrm{~nm}$ (рис. 2,a). В образцах второй серии

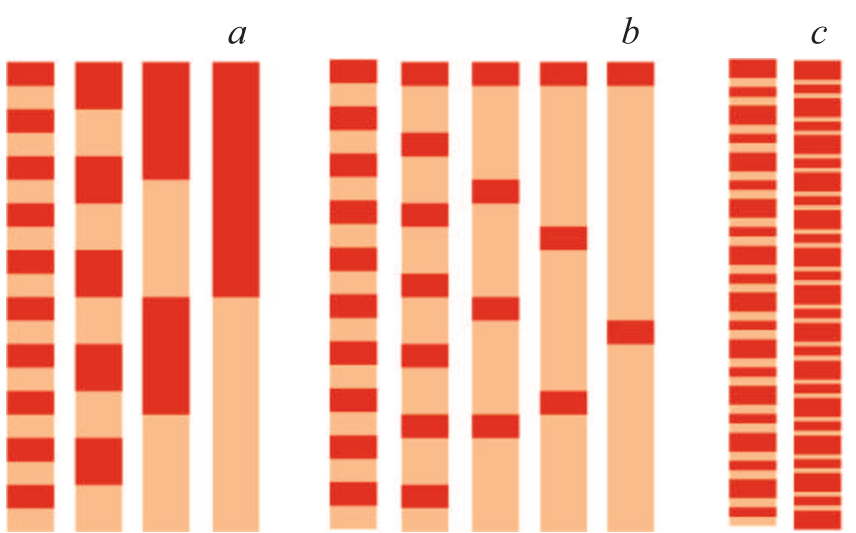

Рис. 2. Схематическое изображение трех серий синтезированных образцов слоевых НП: $a-$ медные и магнитные (кобальт или никель) слои в НП равны между собой по толщине, и варьируются $-50,100,250$ и $500 \mathrm{~nm} ; b-$ магнитный слой имеет толщину $50 \mathrm{~nm}$, а толщина слоев меди варьируются $50,100,200,300$ и $500 \mathrm{~nm} ; c-$ в одном периоде магнитные слои равны 20 и $40 \mathrm{~nm}$, а толщина медных слоев между ними варьируются -20 и $10 \mathrm{~nm}$. слои магнитного металла (кобальта) имели постоянную толщину, а толщина медных слоев (спейсеров) варьировалась от 50 до $500 \mathrm{~nm}$ (рис. 2, $b$ ). В третьей серии образцы НП состояли из чередующихся попарно слоев кобальта с различной толщиной - 40 и $20 \mathrm{~nm}$. Эти магнитные слои разделялись прослойками меди $20 \mathrm{~nm}$ (первый тип образца) или $10 \mathrm{~nm}$ (второй тип образца) (рис. 2,c). Полученные массивы НП были затем аттестованы методом электронной микроскопии.

\section{2. Электронная микроскопия массивов НП}

Полученные массивы НП были изучены методом сканирующей электронной микроскопии в стандартном режиме. Перед исследованием с массивов НП была удалена ростовая полимерная матрица. Примеры полученных СЭМ-изображений представлены на рис. 3.

На полученных изображениях видно чередование слоев различного состава, контраст которых объясняется различной эмиссионной способностью металлов. Элементный анализ (для НП с большой толщиной слоев) позволил выявить чередование состава, соответствовавшее выбранным схемам чередования слоев. Отметим, что для аналогичных НП $(\mathrm{Ni} / \mathrm{Cu})$ со слоями толщиной до $10 \mathrm{~nm}$ в предыдущей работе были получены более информативные ПЭМ изображения [21].

\section{3. Магнитные свойства}

Первая серия образцов. Измерения магнитных свойств первой серии образцов проводились с целью выявления влияния толщины слоев на магнитное поведение массива слоевых НП. НП в этой серии представляли собой чередующиеся слои $\mathrm{Ni} / \mathrm{Cu}$ или $\mathrm{Co} / \mathrm{Cu}$ с одинаковой толщиной для магнитного (никель или кобальт) и немагнитного (медь) материала. Толщина компонентов для различных образцов серии имели значения: 50, 100, 250 и $500 \mathrm{~nm}$ соответственно. 

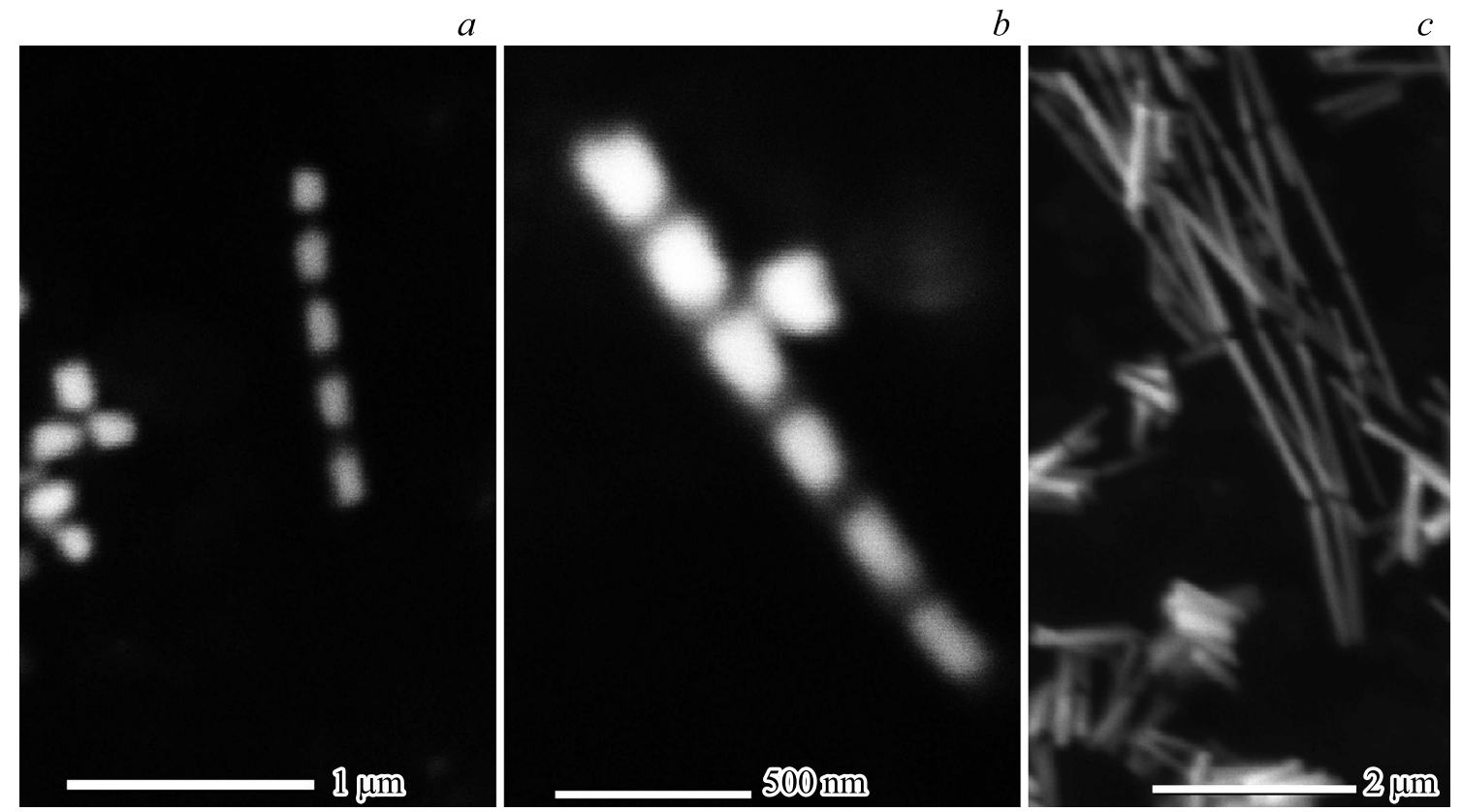

Рис. 3. СЭМ изображения слоевых НП с чередованием Со/Сu (вторая серия). Здесь $a$ и $b-$ НП с толщиной спейсера $100 \mathrm{~nm}$, $c-300 \mathrm{~nm}$.
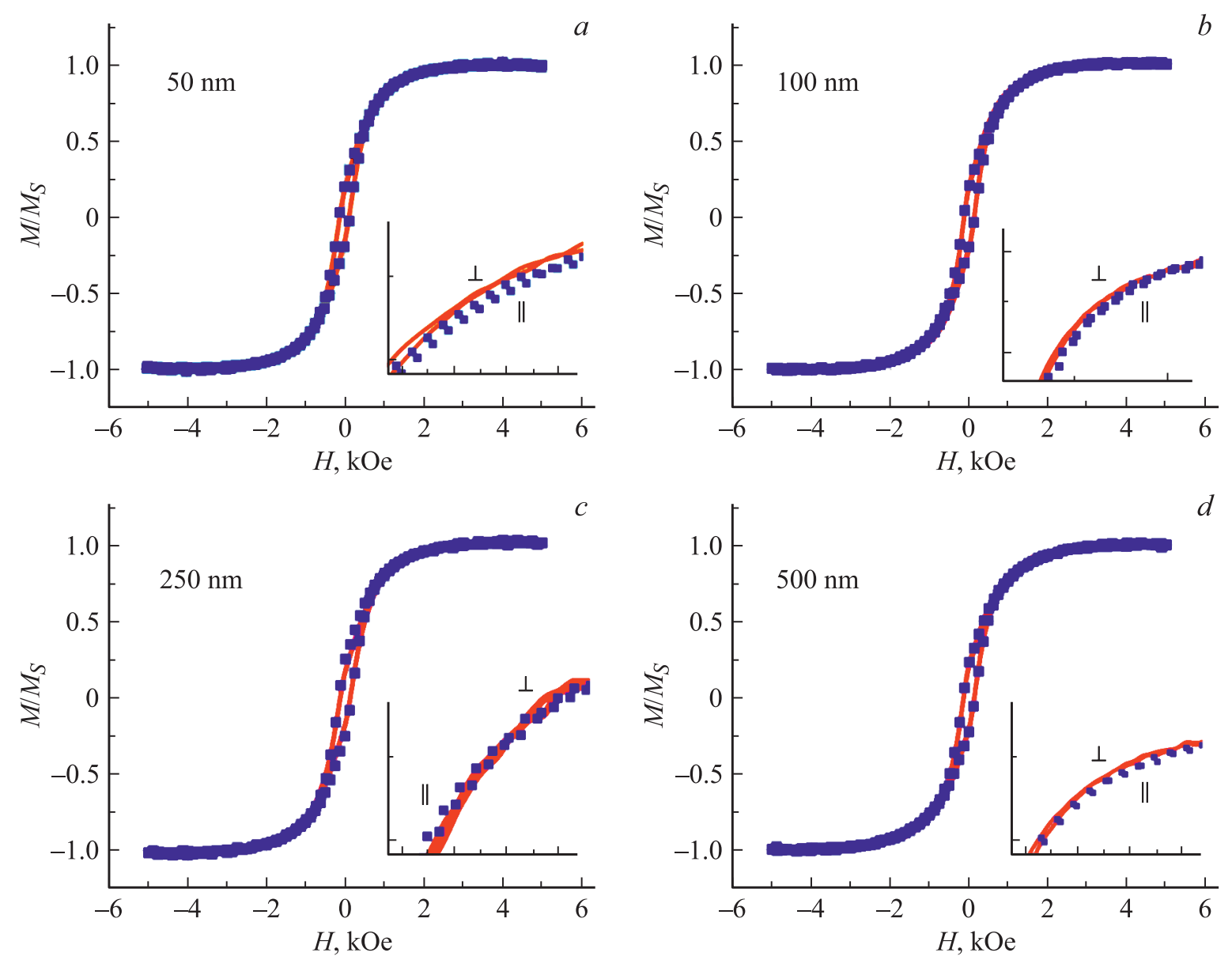

Рис. 4. Кривые магнитного гистерезиса, регистрируемые при параллельной и перпендикулярной ориентациях сканирующего магнитного поля по отношению к оси НП для образцов первой серии со слоями $\mathrm{Ni} / \mathrm{Cu}$ толщиной: $a-50, b-100, c-250, d-$ $500 \mathrm{~nm}$. 

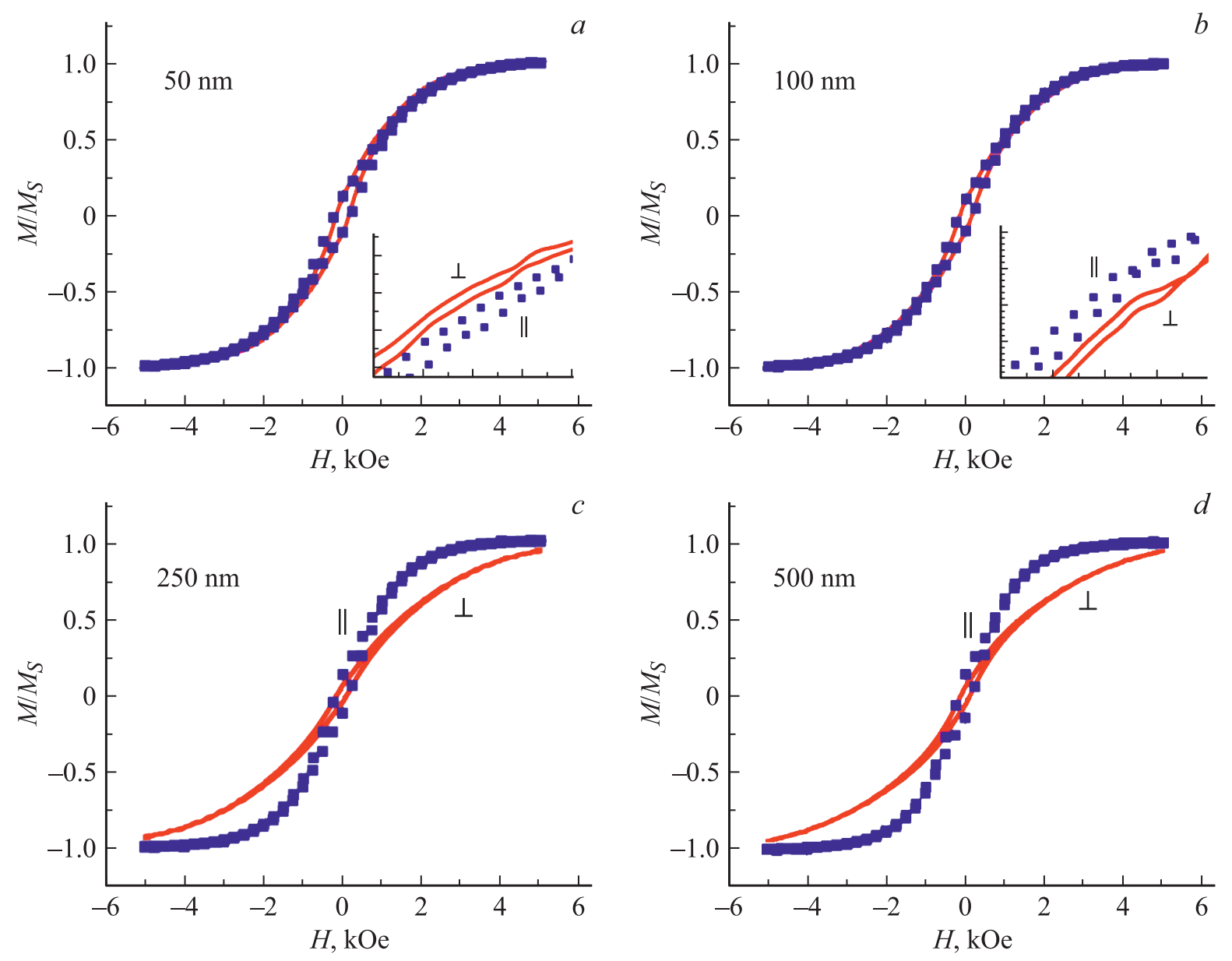

Рис. 5. Кривые магнитного гистерезиса при ориентации магнитного поля параллельно и перпендикулярно оси НП для образцов $\mathrm{Co} / \mathrm{Cu}$ с толщиной слоев $a-50, b-100, c-250, d-500 \mathrm{~nm}$.

На рис. 4 показаны результаты магнитных измерений для образцов с чередованием слоев $\mathrm{Ni} / \mathrm{Cu}$ различной толщины.

Анализ представленных зависимостей показывает несущественные отличия в процессах намагничивания массива НП при сканировании величины магнитного поля, вдоль и перпендикулярно оси НП при любой толщине слоевых сегментов. Этот результат указывает на то, что магнитная анизотропия формы и магнитное диполь-дипольное взаимодействие между слоями никеля в самой НП сравнимы по величине с магнитостатическими взаимодействиями между НП в массиве.

Значительно более интересными оказались зависимости магнитных свойств для образцов массивов $\mathrm{Co} / \mathrm{Cu}$, результаты измерений которых приведены на рис. 5.

Хорошо видно, что для НП с толстыми магнитными слоями - 250 и $500 \mathrm{~nm}$ (т.е. более удлиненными по отношению к диаметру НП) наблюдалась четко выраженная анизотропия магнитных свойств: ось легкого намагничивания совпадала с осью НП, что представляется вполне логичным. Также ожидаемым явилось и то, что образцы НП с толщиной слоев $100 \mathrm{~nm}$ были изотропны по магнитным характеристикам (толщина слоя совпада- ла с диаметром). Результат для наиболее тонких слоев кобальта, $50 \mathrm{~nm}$, оказался неожиданным - магнитное поведение НП оказалось практически изотропным. Учитывая, что в этом случае толщина магнитного слоя $(50 \mathrm{~nm})$ меньше диаметра НП, следовало ожидать, что ось легкого намагничивания будет лежать в плоскости слоя, т.е. перпендикулярно оси НП. Поскольку этого не наблюдалось, можно предположить, что намагниченность не переходит в плоскость слоя из-за сильного магнитостатического взаимодействия соседних слоев в НП, расстояние между которыми весьма мало - $50 \mathrm{~nm}$.

Вторая серия образцов. Чтобы выявить роль взаимодействия (расстояния) между магнитными слоями были синтезированы образцы с постоянной толщиной магнитного слоя кобальта $(50 \mathrm{~nm})$ и с изменяющейся толщиной немагнитной медной прослойки - 50, 100, 200, 300 и $500 \mathrm{~nm}$. Магнитные измерения показали, что для таких слоевых НП $\mathrm{Co} / \mathrm{Cu}$ уже при толщине спейсеров $100 \mathrm{~nm}$ образцы проявляют анизотропное поведение (рис. 6), которое определяется формой магнитного слоя кобальта (сплющенный диск толщиной в $50 \mathrm{~nm}$ с диаметром НП $100 \mathrm{~nm})$. 

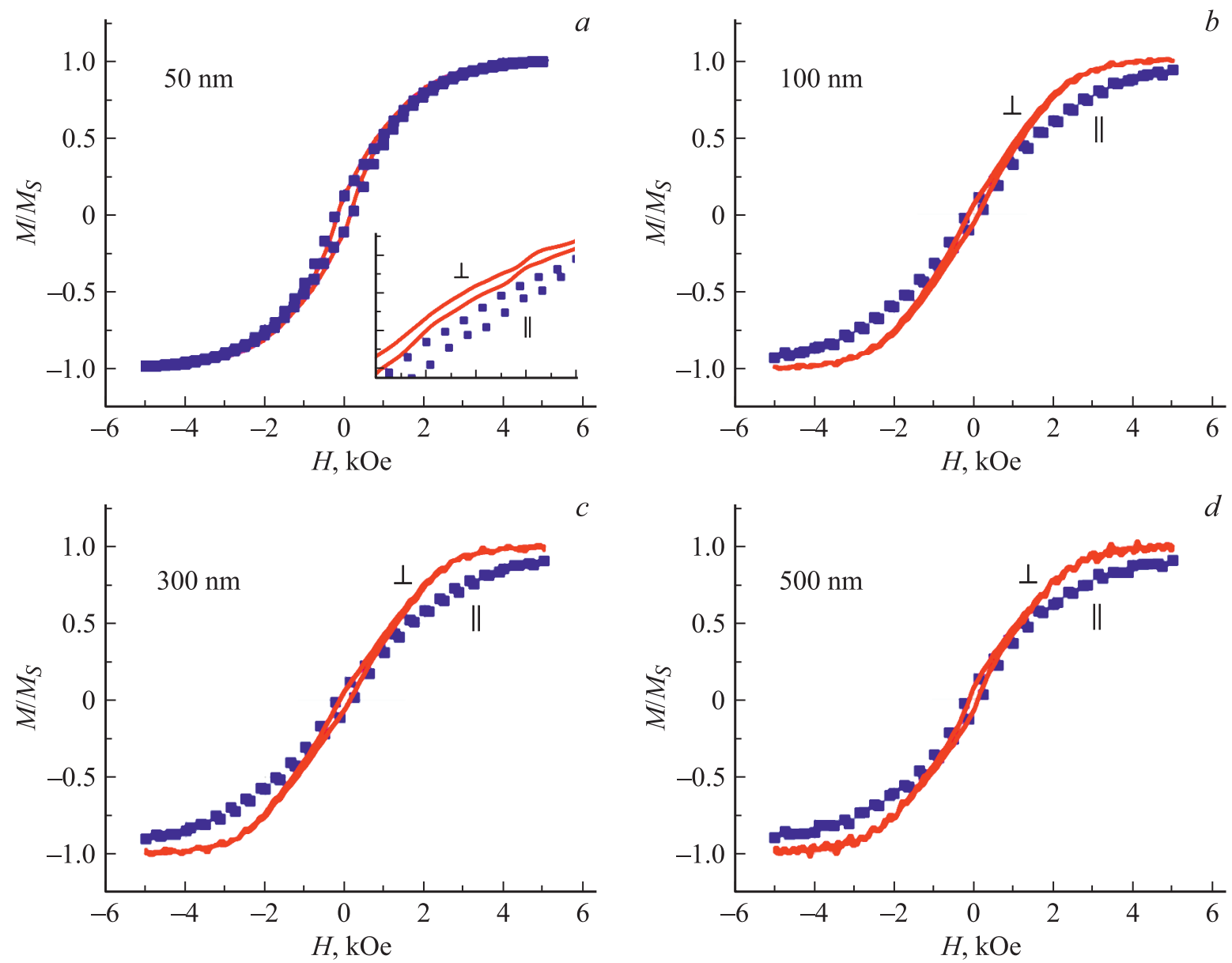

Рис. 6. Кривые магнитного гистерезиса для образцов второй серии, в которой слои кобальта имеют постоянную толщину равную $50 \mathrm{~nm}$, а толщина медной прослойки составляет: $a-50, b-100, c-300$ и $d-500 \mathrm{~nm}$.

При дальнейшем увеличении расстояния между магнитными слоями (толщина спейсеров 200, 300 и $500 \mathrm{~nm}$ ) магнитное поведение слоевых НП практически не меняется - ось легкого намагничивания перпендикулярна оси НП (т.е. лежит в плоскости магнитного слоя). Следовательно, при разделении магнитных слоев более толстыми немагнитными прослойками происходит уменьшение магнитостатического взаимодействия между слоями.

Третья серия образцов. В этом случае изучалось магнитное поведение слоевых НП содержащих два магнитных слоя различной толщины (рис. 7). Конкретно, исследовались массивы НП двух типов: чередующиеся слои кобальта с толщинами 20 и $40 \mathrm{~nm}$ перемежаются медными прослойками толщиной $10 \mathrm{~nm}$ (рис. 7, слева) или $20 \mathrm{~nm}$ (рис. 7, справа).

Наблюдаемое поведение кривых намагничивания можно объяснить тем, что при тонких медных прослойках (толщиной $10 \mathrm{~nm}$ ) магнитные свойства НП приближаются к магнитным свойствам „сплошной“ НП из магнитного металла. Образцы легко намагничиваются вдоль оси роста НП (рис. 7,a). При более толстой медной прослойке $(20 \mathrm{~nm})$ существенный вклад в процесс намаг- ничивания вносит анизотропия формы отдельно взятых слоев кобальта, и массив данных слоевых НП проявляет практически изотропный магнитный отклик (рис. 7,b). Отметим, что аналогичные результаты были получены ранее в работе [21] для $\mathrm{HП} \mathrm{Fe} / \mathrm{Cu}$ : для коротких медных спейсеров дипольное взаимодействие между слоями $\mathrm{Fe}$ определяло магнитные свойства образцов, которые были такими же, как и свойства гомогенных НП Fе такого же размера. В то же время в НП с длинными медными сегментами железные слои проявляют себя как совокупность невзаимодействующих магнитных слоев.

Оценки энергии магнитостатического взаимодействия. Для объяснения полученных выше результатов нами была проведена оценка энергий магнитного диполь-дипольного взаимодействия магнитных слоев в НП и магнитной анизотропии формы в случаях параллельного и перпендикулярного намагничивания НП.

Во всех случаях магнитные слои имеют форму цилиндра, конкретно, во второй серии слои имели толщину $50 \mathrm{~nm}$ и диаметр $100 \mathrm{~nm}$. Для оценки размагничивающего поля посчитаем баллистический коэффициент размагничивания для продольного $(\|)$ и перпендикулярного $(\perp)$ направлений. Наиболее точное приближение 

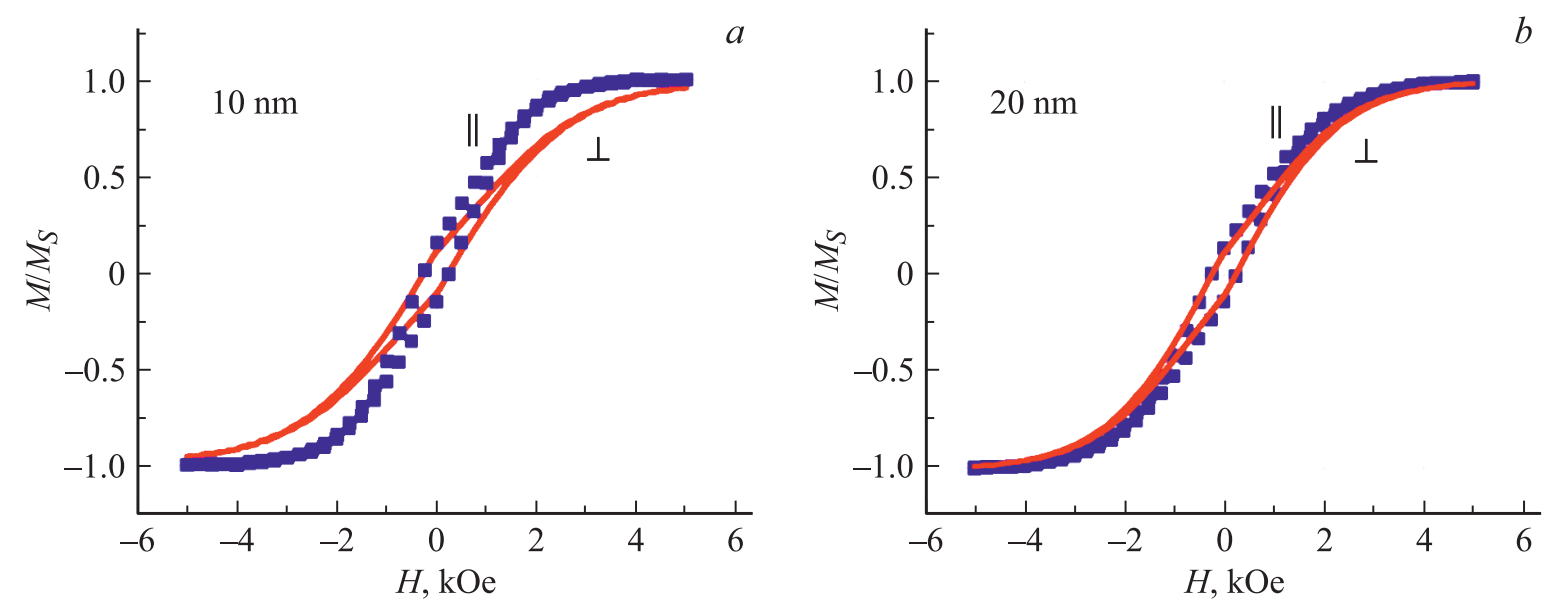

Рис. 7. Кривые магнитного гистерезиса для образцов третьей серии, в которой магнитные слои в одном периоде равны по толщине 20 и $40 \mathrm{~nm}$, а толщина медной прослойки между ними составляет $10(a)$ или $20 \mathrm{~nm}(b)$.

дает формула, предложенная К. Вармутом [24]:

$$
N_{\|}(\lambda) \approx N_{e}(\lambda) \cdot k(\lambda)
$$

где $\lambda$ - отношение полуосей эллипса (в случае цилиндра - отношение толщины цилиндра к его диаметру), $N_{e}(\lambda)$ - баллистический коэффициент размагничивания вдоль длинной оси эллипсоида вращения, $k(\lambda)-$ поправочный коэффициент, приблизительно равный единице.

Для коэффициента размагничивания в перпендикулярном направлении:

$$
N_{\perp}(\lambda) \approx 0.5 \cdot\left(1-N_{\|}(\lambda)\right) .
$$

Подставляя $\lambda=0.5$ (для второй серии образцов) получим значения:

$$
N_{\|}=0.468 ; \quad N_{\perp}=0.266 .
$$

Сделаем оценку энергии магнитостатического взаимодействия. Для этого рассмотрим два соседних диска на расстоянии $L$ друг от друга (рис. 8 ). Обозначим толщину и площадь диска $l$ и $S$ соответственно.

Далее, разобьем каждый из дисков на тонкие слои толщиной $d x$ и проинтегрируем энергию магнитного диполь-дипольного взаимодействия дисков из разных слоев.

В общем виде энергия взаимодействия двух магнитных диполей выглядит следующим образом:

$$
W_{d d}=\frac{1}{2} \frac{\left[\mathbf{m}_{1} \cdot \mathbf{m}_{2} \cdot R^{2}-3\left(\mathbf{m}_{1} \cdot \mathbf{R}\right)\left(\mathbf{m}_{2} \cdot \mathbf{R}\right)\right]}{R^{5}} .
$$

Тогда, если представить магнитный момент одного диска в виде $d \mathbf{m}=d x \cdot S \cdot M \cdot \mathbf{n}_{z}$ (для параллельного намагничивания, $M-$ намагниченность, $\mathbf{n}_{z}-$ единичный вектор, направленный вдоль оси НП), получим

$$
d W_{\|}=-M^{2} S^{2}\left[\frac{d x_{1} d x_{2}}{\left(L-x_{1}+x_{2}\right)^{3}}\right] .
$$

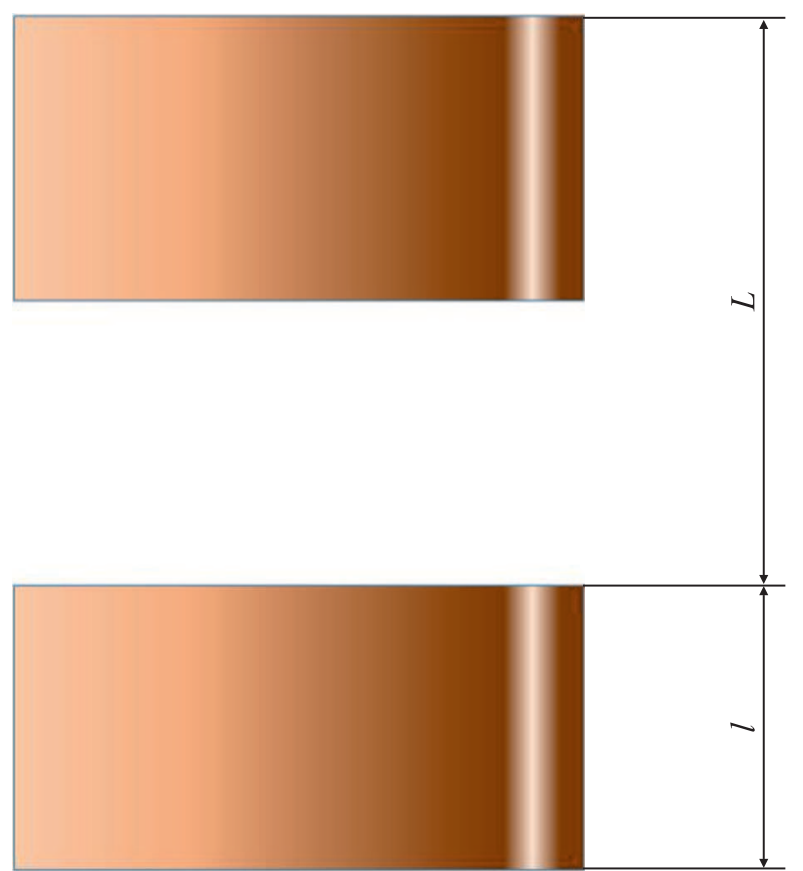

Рис. 8. Схематическое изображение магнитных слоев в слоевой НП. Здесь $l-$ толщина слоя, а $L-$ расстояние между слоями.

После интегрирования от 0 до $l$ получим следующее выражение:

$$
\begin{aligned}
W_{\|} & =-\frac{M^{2} S^{2}}{2}\left[\frac{1}{L-l}-\frac{2}{L}+\frac{1}{L+l}\right] \\
& =-\frac{M^{2} S^{2}}{2} \frac{2 l^{2}}{L\left(L^{2}-l^{2}\right)}=-\frac{m^{2}}{L\left(L^{2}-l^{2}\right)},
\end{aligned}
$$

где $m=M S l-$ магнитный момент одного слоя. Здесь хорошо видно, что учет толщины магнитного слоя $(l)$ дает $L^{2}-l^{2}$ в знаменателе, что в случае тонких про- 
слоек отличается от взаимодействия точечных диполей, находящихся на расстояние $L$, на $33 \%$. Заметим, что тот же результат можно получить, если рассмотреть модель поверхностных магнитных зарядов [25] и посчитать магнитостатическую энергию в квазиодномерном случае, типичном для НП. Отметим, что у большинства слоев в образце НП есть два соседа, энергии взаимодействия с которыми складываются (взаимодействием с более удаленными, не соседними, слоями в НП учтем ниже), однако посчитанная энергия уже включает в себя два слоя, поэтому в расчет энергии на один слой магнитостатическая энергия войдет в полученном выше виде.

На следующем шаге наших оценок посчитаем вклад дальних слоев в магнитостатическую энергию отдельной НП. Для этого необходимо сосчитать следующую сумму:

$$
W_{\|}=\sum_{n=1}^{\infty}-\frac{m^{2}}{n L\left(\left((n L)^{2}-l^{2}\right)\right.}=-m^{2} \rho^{3} \sum_{n=1}^{\infty} \frac{1}{n^{3}\left(1-\frac{\rho^{2}}{n^{2}}\right)},
$$

где $\rho=l / L-$ фактор заполнения. Здесь для удобства расчетов положим $l=1$ и разложим знаменатель: $1-\rho^{2} / n^{2}$ в ряд:

$$
\begin{aligned}
W_{\|} & =-m^{2} \rho^{3}\left\{\sum_{n=1}^{\infty} \frac{1}{n^{3}}+\rho^{2} \sum_{n=1}^{\infty} \frac{1}{n^{5}}+\ldots\right\} \\
& =-m^{2} \rho^{3}\left(\xi(3)+\rho^{2} \xi(5)+\ldots\right),
\end{aligned}
$$

где $\xi(x)$ - дзета-функция Римана. Для оценки значения дзета-функции с аргументом, большим пяти, можно считать равными единице, что в итоге дает сходящийся ряд

$$
\begin{aligned}
W_{\|} & =-m^{2} \rho^{3}\left(\xi(3)+\rho^{2}+\rho^{4}+\ldots\right) \\
& =-m^{2} \rho^{3}\left(\frac{1}{1-\rho^{2}}+\zeta(3)-1\right) .
\end{aligned}
$$

В формуле (8) первое слагаемое учитывает геометрические размеры магнитного слоя, а второе - вклад удаленных слоев в общую энергию отдельно взятой НП. В случае тонких прослоек (например, $\rho=0.5$ ) первое слагаемое равняется 1.333, тогда как значение $\zeta(3) \approx 1.2$. Однако с уменьшением фактора заполнения $\rho$ первое слагаемое быстро убывает, стремясь к единице, поэтому для построения полной картины при всех факторах заполнения необходим учет обоих слагаемых.

Оценим вклад магнитного диполь-дипольного взаимодействия между НП в полную магнитостатическую энергию отдельной НП. Для этого необходимо сосчитать энергию взаимодействия одного слоя со всеми магнитными слоями в соседних НП. Принимая во внимание, что расстояние между магнитными слоями в соседних НП существенно выше, чем геометрические размеры слоя, будем рассматривать каждый слой как точечный магнитный диполь. Тогда выражение для энергии магнитостатического взаимодействия при намагничивании вдоль оси НП примет следующий вид:

$$
W_{\| \text {cross }}=\int \sum_{\Delta Z} \frac{1}{2}\left\{\frac{m_{1} m_{2}\left(R^{2}+\Delta Z^{2}\right)-3 m_{1} m_{2} \Delta Z^{2}}{\left(R^{2}+\Delta Z^{2}\right)^{5 / 2}}\right\} \sigma_{0} d S
$$

где $R$ - расстояние между двумя НП, $\Delta Z-$ разница координат $Z$ двух слоев в отдельно взятой НП в цилиндрической системе координат, $\sigma_{0}-$ плотность вероятности нахождения НП на элементе площади $d S$, равная поверхностной плотности пор ростовой матрицы, что, фактически, соответствует поверхностной концентрации НП. После интегрирования по углам и перемены порядка суммирования и интегрирования получаем

$$
W_{\| c r o s s}=\frac{1}{2} \pi m^{2} \sigma_{0} \sum_{k=-\infty}^{\infty} \int_{R^{*}}^{\infty} \frac{R^{2}-2(k L)^{2}}{\left(R^{2}+(k L)^{2}\right)^{5 / 2}} d R^{2} .
$$

Здесь разницу координат между слоями в НП мы выразили как $\Delta Z=k L, k-$ натуральный ряд чисел, а $L$ - период чередования слоев в НП. В качестве $R^{*}$ (минимального расстояния между НП) возьмем их диаметр $-100 \mathrm{~nm}\left(R^{*}=2\right.$ в относительных единицах, где $l=1)$. После интегрирования выражения (10) получаем

$$
\begin{aligned}
W_{\| c r o s s} & =4 \pi m^{2} \sigma_{0} \sum_{k=-\infty}^{\infty} \frac{1}{\left(4+(k L)^{2}\right)^{3 / 2}} \\
& =4 \pi m^{2} \sigma_{0} \rho^{3} \sum_{k=-\infty}^{\infty} \frac{1}{\left(4 \rho^{2}+k^{2}\right)^{3 / 2}} .
\end{aligned}
$$

В случае намагничивания массива НП перпендикулярно оси НП проводятся аналогичные вычисления, где интегрирование по углам дает коэффициент 1/2, которые приводят к следующему результату:

$$
W_{\perp \text { cross }}=-2 \pi m^{2} \sigma_{0} \rho^{3} \sum_{k=-\infty}^{\infty} \frac{1}{\left(4 \rho^{2}+k^{2}\right)^{3 / 2}}=-\frac{1}{2} W_{\| \text {cross }} .
$$

В итоге для случая параллельного намагничивания получаем следующее выражения для полной магнитной энергии отдельного слоя НП:

$$
\begin{aligned}
E_{\|}= & W_{\|}+\frac{W_{\| \text {cros } s}}{2}+W_{\| \text {form }}=-\pi^{2} \rho^{3}\left[\frac{1}{1-\rho^{2}}+\zeta(3)-1\right] \\
& +2 \pi^{3} \sigma_{0} \rho^{3} \sum_{k=-\infty}^{\infty} \frac{1}{\left(4 \rho^{2}+k^{2}\right)^{3 / 2}}+\frac{N_{\|} \pi}{2}
\end{aligned}
$$

Для перпендикулярного направления:

$$
\begin{aligned}
E_{\perp}= & W_{\perp}+\frac{W_{\perp \text { cross }}}{2}+W_{\perp \text { form }}=\frac{\pi^{2} \rho^{3}}{2}\left[\frac{1}{1-\rho^{2}}+\zeta(3)-1\right] \\
& -\pi^{3} \sigma_{0} \rho^{3} \sum_{k=-\infty}^{\infty} \frac{1}{\left(4 \rho^{2}+k^{2}\right)^{3 / 2}}+\frac{N_{\perp} \pi}{2}
\end{aligned}
$$




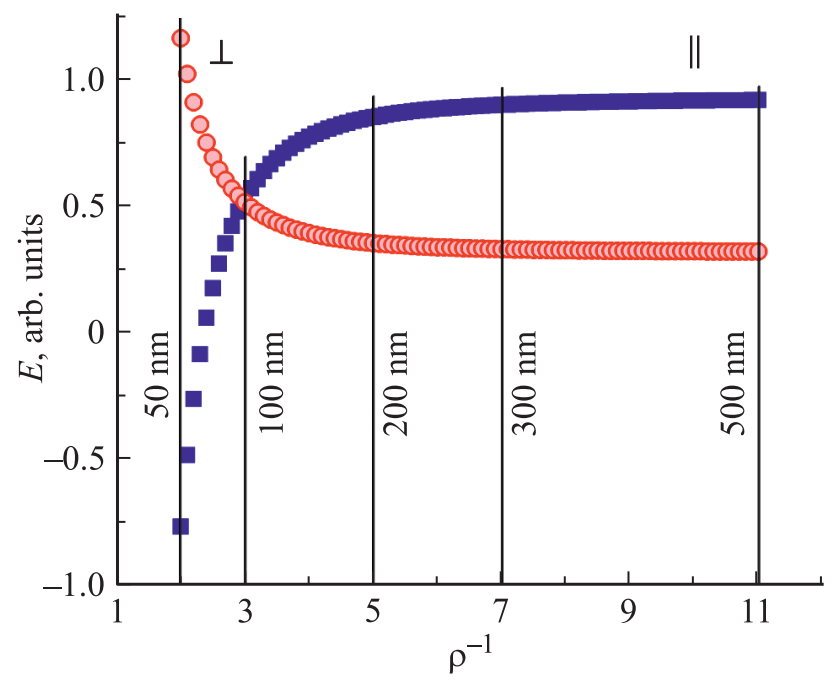

Рис. 9. Зависимость полной магнитной энергии слоевой НП от обратного значения фактора заполнения ее магнитным металлом $\rho^{-1}$ в поле насыщения при параллельной $(\|)$ и перпендикулярной $(\perp)$ ориентациях вектора намагниченности по отношению к оси НП. Тонкими вертикальными линиями показаны значения величины $\rho^{-1}$, соответствующие различным толщинам медной прослойки (от 50 до $500 \mathrm{~nm}$ ) при постоянной толщине магнитного слоя $50 \mathrm{~nm}$ для сравнения с данными, приведенными на рис. 6.

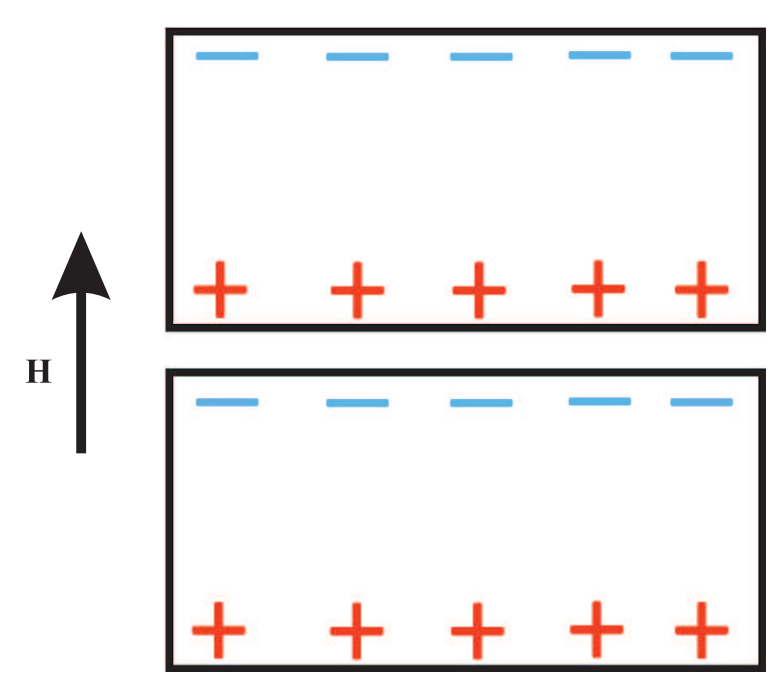

Рис. 10. Схематическое изображение распределения поверхностных магнитных зарядов при малом расстоянии между магнитными слоями в слоевой НП с фактором заполнения магнитным металлом, близким к единице $(\rho \approx 1)$.

Подставив численные значения плотности $\sigma_{0}$, а также коэффициенты анизотропии формы $N_{\perp}$ и $N_{\|}$, можно построить графики зависимостей суммарной магнитостатической энергии слоя НП от обратного значения фактора заполнения $\rho^{-1}$ в случае параллельного и перпендикулярного намагничивания, которые приведены на рис. 9.
Как видно из представленных кривых, при увеличении толщины прослойки (расстояния между магнитными слоями) и, соответственно, роста обратного значения фактора заполнения $\rho^{-1}$ происходит переход от энергетически более выгодного намагничивания вдоль оси НП к намагничиванию перпендикулярно оси НП, что качественно отражает полученные результаты измерений кривых намагничивания во второй и третьей сериях экспериментов. (рис. 6). Заметим, что при толщинах медной прослойки 50 и $100 \mathrm{~nm}$ наши оценки являются достаточно грубыми из-за геометрических ограничений применимости модели точечного диполя.

В отношении результатов магнитных измерений третьей серии образцов следует отметить, что теория размагничивающего поля основана на модели поверхностных зарядов и в ней рассматривается только изолированный магнитный объект во внешнем магнитном поле. В этой серии образцов близость магнитных слоев друг к другу в НП может приводить к перераспределению поверхностных зарядов в слое (рис. 10), что в свою очередь приводит к неприменимости теории размагничивающего поля. Этим можно объяснить необычное поведение ориентационной зависимости кривой намагничивания в третьей серии. Когда толщина медных прослоек $(10$ и $20 \mathrm{~nm})$ меньше (или равна) толщине магнитных слоев $(20$ и $40 \mathrm{~nm})$, заряды распределяются по поверхности интерфейса магнитный/немагнитный слой, образуя однородное размагничивающее поле, направленное вдоль оси НП. В процессе намагничивания вдоль оси НП часть энергии, затрачиваемой на распределение зарядов, компенсируется близостью полюсов соседних дисков. Следовательно, массивы слоевых НП с малой толщиной немагнитной прослойки легче намагнитить вдоль оси роста НП, чем перпендикулярно ей, даже несмотря на тот факт, что аспектное отношение толщины отдельного магнитного слоя к его диаметру существенно меньше единицы.

\section{4. Заключение}

Анализ полученных результатов позволяет заключить, что метод матричного синтеза является эффективным способом получения слоевых нанопроволок с чередованием слоев $\mathrm{Ni} / \mathrm{Cu}$ или $\mathrm{Co} / \mathrm{Cu}$ с различными геометрическими параметрами. В частности, были синтезированы и исследованы три группы образцов слоевых НП с диаметром $100 \mathrm{~nm}$, в которых: 1) толщина обоих магнитных/немагнитных слоев варьировалась в широком диапазоне от 50 до $500 \mathrm{~nm}$; 2) толщина магнитного слоя была постоянной $(50 \mathrm{~nm})$, а толщина немагнитной медной прослойки изменялась от 50 до $500 \mathrm{~nm}$ и 3) образцы слоевых НП состояли из чередующихся попарно слоев кобальта с различной толщиной (40 и $20 \mathrm{~nm}$ ), разделенные прослойками меди в 10 или $20 \mathrm{~nm}$. Установлено, что не только аспектное отношение толщины магнитного слоя к его диаметру, но и расстояние 
между соседними магнитными слоями в нанопроволоке определяет направление оси легкого намагничивания и магнитную анизотропию массива синтезированных слоевых НП. Расчет зависимости полной магнитостатической энергии слоевой НП в поле насыщения от обратного значения фактора заполнения ее магнитным металлом качественно подтверждает экспериментально наблюдаемые результаты исследования магнитного поведения синтезированных массивов слоевых НП с различной толщиной медной прослойки.

\section{Благодарности}

Авторы благодарны П.Ю. Апелю (ОИЯИ, Дубна) за предоставление образцов полимерных матриц.

\section{Финансирование работы}

Работы проводились при поддержке Министерства образования и науки РФ в рамках выполнения работ по государственным заданиям ФНИЦ „Кристаллография и фотоника“" РАН и КФТИ ФИЦ КазНЦ РАН, АААА-А18118041760011-2 Микроскопические исследования проведены в рамках гранта РФФИ, 18-02-00515_а.

\section{Конфликт интересов}

Авторы заявляют, что у них нет конфликта интересов.

\section{Список литературы}

[1] C.R. Martin. Science 266, 5193, 1961 (1994).

[2] A. Fert, L. Piraux. J. Magn. Magn. Mater. 200, 338 (1999).

[3] T. Thurn, T. Albrecht, J. Schotter, G.A. Kastle, N. Emley, T. Shibauchi, L. Krusin-Elbaum, K. Guarini, C.T. Black, M.T. Tuominen, T.P. Russell. Science 290, 5499, 2126 (2000).

[4] H. Schlorb, V. Haehnel, M.S. Khatri, A. Srivastav, A. Kumar, L. Schultz, S. Fahler. Phys. Status Solidi B 247, 10, 2364 (2010).

[5] Y.P. Ivanov, A. Chuvilin, S. Lopatin, J. Kosel. ACS Nano 10, 5,5326 (2016).

[6] Ю.В. Гуляев, С.Г. Чигарев, А.И. Панас, Е.А. Вилков, Н.А. Максимов, Д.Л. Загорский, А.С. Шаталов. ПЖТФ 45, 6, 26 (2019).

[7] J.-G. Zhu. Proc. IEEE 96, 1786 (2008).

[8] С.Н. Вдовичев, Б.А. Грибков, С.А. Гусев, А.Ю. Климов, В.Л. Миронов, И.М. Нефедов, В.В. Рогов, А.А. Фраерман, И.А. Шерешевский. Письма в ЖЭТФ 94, 5, 418 (2011).

[9] A.A. Fraerman, B.A. Gribkov, S.A. Gusev, A.Yu. Klimov, V.L. Mironov, D.S. Nikitushkin, V.V. Rogov, S.N. Vdovichev, B. Hjorvarsson, H. Zabel. J. Appl. Phys. 103, 073916 (2008).

[10] L. Piraux, J.M. George, J.F. Despres, C. Leroy, E. Ferain, R. Legras. Appl. Phys. Lett. 65, 2484 (1994).

[11] A. Blondel, B. Doudin, J.-Ph. Ansermet. J. Magn. Magn. Mater. 165, 34 (1997).

[12] J. Wong, P. Greene, R.K. Dumas, K. Lui. Appl. Phys. Lett. 94, 032504 (2009).

[13] M. Chen, C.-L. Chien, P.C. Searson. Chem. Mater. 18, 6, 1595 (2006).
[14] M. Chen, P.C. Searson, C.L. Chien. J. Appl. Phys. 93, 8253 (2003).

[15] L.-P. Carignan, Ch. Lacroix, A. Ouimet, M. Ciureanu, A. Yelon, D. Menard. J. Appl. Phys. 102, 023905 (2007).

[16] N. Maleak, P. Potpattanapol, N.N. Bao, J. Ding, W. Wongkokuo, I.M. Tang, S. Thongme. J. Magn. Magn. Mater. KD 354, 262 (2014).

[17] A. Shirazi Tehrani, M. Almas Kashi, A. Ramazani, A.H. Montaze. Superlattices Microstruct. 95, 38 (2016).

[18] F. Beron, L.P. Carignan, D. Menard, A. Yelon. IEEE Trans. Magn. 44, 11 (2008).

[19] M. Susano, M.P. Proenca, S. Moraes, C.T. Sousa, J.P. Araújo. Nanotechnology 27, 335301 (2016).

[20] S. Moraes, D. Navas, F. Béron, M.P. Proenca, K.R. Pirota, C.T. Sousa, J.P. Ara ujo. Nanomaterials, 8, 490 (2018).

[21] Д.Л. Загорский, И.М. Долуденко, Д.А. Черкасов, О.М. Жигалина, Д.Н. Хмеленин, И.М. Иванов, Д.А. Бизяев, Р.И. Хайбулин, С.А. Шаталов. ФТТ 61, 9, 1682 (2019).

[22] И.М. Долуденко, Д.Б. Трушина, Т.Н. Бородина, Т.В. Букреева, Д.Л. Загорский. Тез. докл. III Междунар. конф. со шк. молодых ученых „Физика - наукам о жизни“. ФТИ им. А.Ф. Иоффе, СПб (2019). С. 216.

[23] Д.К. Нургалиев, П.Г. Ясонов. Коэрцитивный спектрометр. Патент РФ на полезную модель № 81805. Бюл. ФИПС № 9. (2009).

[24] K. Warmuth. Archiv Fur Elektrotechnik 41, 5, 242 (1954).

[25] С.В. Вонсовский. Магнетизм. Наука, М. (1971). С. 786.

Редактор Е.Ю. Флегонтова 